\title{
Relationship between amino acid composition and gene expression in the mouse genome
}

\author{
Kazuharu Misawa ${ }^{1,2^{*}}$, Reiko F Kikuno ${ }^{3}$
}

\begin{abstract}
Background: Codon bias is a phenomenon that refers to the differences in the frequencies of synonymous codons among different genes. In many organisms, natural selection is considered to be a cause of codon bias because codon usage in highly expressed genes is biased toward optimal codons. Methods have previously been developed to predict the expression level of genes from their nucleotide sequences, which is based on the observation that synonymous codon usage shows an overall bias toward a few codons called major codons. However, the relationship between codon bias and gene expression level, as proposed by the translation-selection model, is less evident in mammals.

Findings: We investigated the correlations between the expression levels of 1,182 mouse genes and amino acid composition, as well as between gene expression and codon preference. We found that a weak but significant correlation exists between gene expression levels and amino acid composition in mouse. In total, less than 10\% of variation of expression levels is explained by amino acid components. We found the effect of codon preference on gene expression was weaker than the effect of amino acid composition, because no significant correlations were observed with respect to codon preference.
\end{abstract}

Conclusion: These results suggest that it is difficult to predict expression level from amino acid components or from codon bias in mouse.

\section{Background}

Codon bias is a phenomenon that refers to the differences in the frequencies of occurrence of synonymous codons among different genes [1]. In the translationselection model, natural selection is considered to be a cause of codon bias, because codon usage in highly expressed genes is biased toward "optimal" codons, i.e., codons corresponding to more abundant tRNAs in many organisms [2-6]. Methods have previously been developed to predict the expression level of genes from their nucleotide sequences, which is based on the observation that synonymous codon usage shows an overall bias toward a few codons called major codons [2-12].

Previous studies have provided clear evidence that the translation-selection model applies to some prokaryotes, such as Escherichia coli $[6,13]$, but not to all bacteria

\footnotetext{
* Correspondence: kazumisawa@riken.jp

${ }^{1}$ Research Program for Computational Science, Research and Development Group for Next-Generation Integrated Living Matter Simulation, Fusion of Data and Analysis Research and Development Team, RIKEN, 4-6-1 Shirokanedai, Minato-ku, Tokyo 108-8639, Japan

Full list of author information is available at the end of the article
}

[4]. Additionally, some evidence exists that suggests this model is also applicable to various eukaryotes, including Saccharomyces cerevisiae [14-17], Caenorhabditis elegans $[18,19]$, and the fruit fly $[16,20]$, and even to the vertebrate Xenopus laevis [21]. However, the relationship between codon bias and expression level as proposed by the translation-selection model is less evident in mammals [22-30]. Urrutia and Hurst [23] found a weak correlation between gene expression levels and codon bias in human, but failed to find a relationship between this correlation and tRNA-gene copy numbers.

Amino acid content is also known to be dependent on gene expression level in some bacteria [31,32], as well as in budding yeast [8]. To determine why the relationship between codon bias and gene expression level, as proposed by the translation-selection model, is less evident in mammals, we investigated the correlations between the expression levels of genes and both the amino acid contents of genes and codon preference, in mouse. Subsequently, we compared the effect of gene expression on codon preference to the effect of gene expression on

C Biomed Central

(C) 2011 Misawa et al; licensee BioMed Central Ltd. This is an open access article distributed under the terms of the Creative Commons Attribution License (http://creativecommons.org/licenses/by/2.0), which permits unrestricted use, distribution, and reproduction in any medium, provided the original work is properly cited. 
amino acid composition. We used the expression data of mouse genes contained in the InGap database [33].

\section{Materials and methods Mouse Genes}

We obtained cDNA sequences of genes of Mus musculus from the ROUGE (http://www.kazusa.or.jp/rouge/ index.html) database [34]. In total, 449,444 codons from 1,182 genes were used. Mouse expression data were retrieved from the InGap database using cDNA microarray [33].

\section{Amino Acid Contents and Codon Preference}

We calculated the proportion of the amino acid contents of all genes. In order to examine the translationselection model, we classified amino acids into two classes, i.e., C- and T-adapted, on the basis of tRNAgene copy numbers in the mouse genome, since tRNAgene copy numbers can be considered as a rough estimate of tRNA abundance [26]. If natural selection is a cause of codon bias, codon usage in C-adapted amino acids of highly expressed genes will be biased toward $\mathrm{C}$-ending codons and vice versa. First, we defined Cending and T-ending codons; for instance, AGC is a Cending codon and AGT is a T-ending codon. However, both encode the Ser residue. In the mouse genome, when the number of tRNAs complementary to C-ending codons for an amino acid is larger than the number of tRNAs that are complementary to T-ending codons, the amino acid is defined as a $\mathrm{C}$-adapted amino acid. If the opposite is true, the amino acid is instead classified as a $\mathrm{T}$-adapted amino acid. Furthermore, an amino acid is classified as T-adapted when the number of tRNAs that are complementary to C-ending codons is the same as the number of tRNAs that are complementary to Tending codons. We obtained the number of tRNAs in the mouse genome from the GtRNAdb database [35]. Ser, Leu, Pro, Arg, Ile, Thr, Val, and Ala are T-adapted amino acids, whereas Phe, Tyr, Cys, His, Asn, Ser, Asp, and Gly are $\mathrm{C}$-adapted amino acids. Of note, Ser is encoded by TCT, TCC, TCA, TCG, AGC, and AGT. The number of tRNAs that are complementary to TCT is larger than the number that are complementary to TCC, whereas the number of tRNAs that are complementary to AGT is smaller than the number that are complementary to AGC. We considered the two types of codons that specifically encoded Ser. We compared the expression levels of genes to the nucleotide composition at the 3rd position of the codons. We conducted this comparison for all amino acids, including the for $\mathrm{T}$-adapted, and $\mathrm{C}$-adapted amino acids

Because of CpG hypermutability, the mutation rates of codons are affected by the 3 ' adjacent codon [36,37]. Thus, the frequency of codon occurrence is dependent on the adjacent amino acid $[36,38,39]$. We analyzed the effect of adjacent nucleotides on amino acid composition. Specifically, we calculated the correlation between the proportion of the first and third nucleotides of the 3 ' adjacent codon in genes and the expression levels of those genes.

\section{Analysis}

The Pearson product-moment correlation coefficients were calculated using $R$ software [40]. Because the probability density functions of the amino acid contents, codon preference, and expression levels are not known, we used a Kendall test, which is a nonparametric correlation test. Some of highly expressed genes might have specific sequences and functions. Thus, we eliminated the outliers from the data; we defined outliers as both the $5 \%$ of genes with the highest expression levels and the $5 \%$ of genes with the lowest expression levels. We also conducted multiple-regression analysis.

\section{Results}

\section{Correlation between amino acid contents and gene expression level}

Figure 1 shows a scatter plot of amino acid contents and gene expression levels from the analysis of the mouse genome. Genes were sorted into bins of 50 genes by their expression level when this scatter plot was prepared. Subsequently, the 50 genes were concatenated as a single large gene, and the amino acid contents of the proteins were calculated. Each point on the plot represents a bin. For correlation analyses, we did not use these bins, but instead used each gene as a single entity. Figure 1 shows that the bin with highest expression level was exceptional. We also examined the sequence lengths, GC contents, and gene functions of highly expressed genes by using the ROUGE database [34], but we did not find any specific features.

Table 1 shows the correlation between amino acid composition and the gene expression level. The italicized numbers are the values that were calculated after eliminating the outliers. After the outliers were eliminated, the correlation test was performed. The contents of both Cys and His showed significant negative correlations with the expression level, whereas the content of Ile showed a significant positive correlation with the expression level. Multiple regression analysis showed that the multiple $R^{2}$ is 0.0797 and the adjusted $R^{2}$ is 0.06465 when all of amino acid components were used as predictors. After the outliers were eliminated, the multiple $R^{2}$ is 0.07193 and the adjusted $R^{2}$ is 0.0550 when all of amino acid components were used as predictors. These values of $\mathrm{R}^{2}$ indicate that more than $90 \%$ of variation of expression levels cannot be explained by amino acid components. 


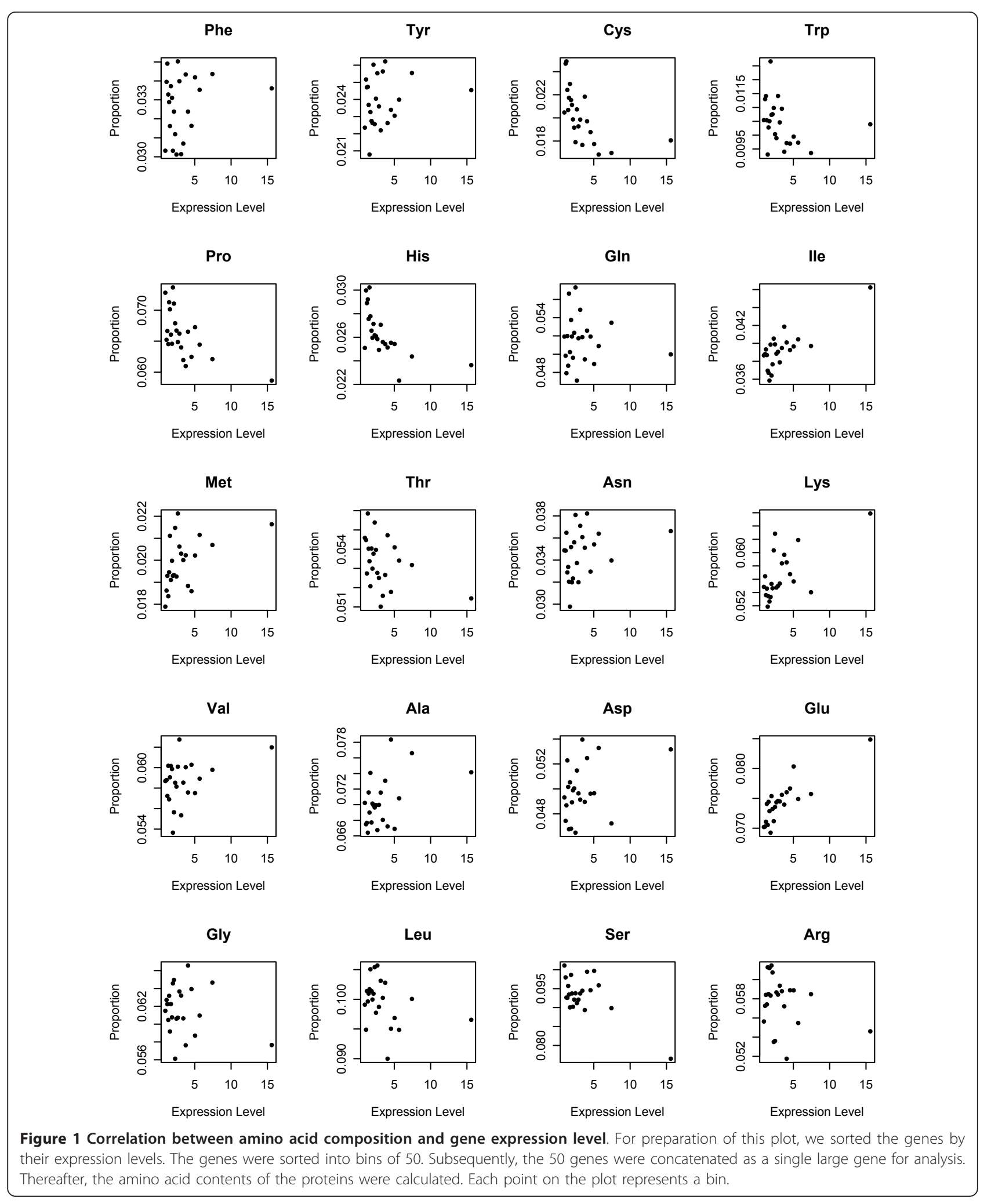


Table 1 Correlation between amino acid abundance and gene expression level

\begin{tabular}{|c|c|c|c|c|c|c|}
\hline \multirow[b]{2}{*}{$\begin{array}{l}\text { Amino } \\
\text { Acid }\end{array}$} & \multicolumn{3}{|c|}{ Overall } & \multicolumn{3}{|c|}{$\begin{array}{c}\text { After Elimination of } \\
\text { Outliers }\end{array}$} \\
\hline & $\begin{array}{l}\text { Correlation } \\
\text { coefficient }\end{array}$ & P-value & & $\begin{array}{l}\text { Correlation } \\
\text { coefficient }\end{array}$ & P-value & \\
\hline Phe & 0.091 & 0.002 & * & 0.067 & 0.030 & \\
\hline Leu & -0.060 & 0.040 & & -0.047 & 0.124 & \\
\hline Ser & -0.123 & 0.000 & $* *$ & -0.055 & 0.071 & \\
\hline Tyr & 0.046 & 0.114 & & 0.059 & 0.055 & \\
\hline Cys & -0.090 & 0.002 & * & -0.118 & 0.000 & ** \\
\hline Trp & -0.052 & 0.074 & & -0.031 & 0.319 & \\
\hline Pro & -0.080 & 0.006 & * & -0.062 & 0.045 & \\
\hline $\mathrm{His}$ & -0.125 & 0.000 & $* *$ & -0.169 & 0.000 & ** \\
\hline Gln & -0.053 & 0.067 & & -0.010 & 0.757 & \\
\hline Arg & -0.061 & 0.036 & & -0.033 & 0.281 & \\
\hline Ile & 0.135 & 0.000 & $* *$ & 0.084 & 0.006 & * \\
\hline Met & 0.060 & 0.040 & & 0.054 & 0.081 & \\
\hline Thr & -0.040 & 0.174 & & -0.045 & 0.141 & \\
\hline Asn & 0.065 & 0.025 & & 0.030 & 0.328 & \\
\hline Lys & 0.091 & 0.002 & * & 0.031 & 0.308 & \\
\hline Val & 0.091 & 0.002 & * & 0.069 & 0.024 & \\
\hline Ala & 0.037 & 0.199 & & 0.072 & 0.018 & \\
\hline Asp & 0.101 & 0.000 & $* *$ & 0.054 & 0.079 & \\
\hline Glu & 0.084 & 0.004 & $*$ & 0.066 & 0.032 & \\
\hline Gly & 0.004 & 0.884 & & 0.018 & 0.567 & \\
\hline
\end{tabular}

* Significant at $1 \%$ level.

** Significant at $0.1 \%$ level.

Codon preference and gene expression level

Table 2 shows the correlation between gene expression levels and codon preference among mouse genes. This data revealed no significant correlations between codon preference and gene expression level. Thus, the effect of

Table 2 Correlation between the nucleotide composition at the $3^{\text {rd }}$ position of codons and gene expression level

\begin{tabular}{ccc}
\hline 3' adjacent nucleotide & Overall & After elimination of outliers \\
\hline All amino acids & & -0.064 \\
T & -0.063 & -0.054 \\
C & -0.061 & -0.048 \\
A & -0.068 & 0.019 \\
G & 0.020 & \\
T-adapted amino acids & & -0.068 \\
T & -0.069 & -0.033 \\
C & -0.051 & -0.050 \\
A & -0.065 & 0.000 \\
G & 0.012 & \\
C-adapted amino acids & & -0.061 \\
T & -0.049 & -0.061 \\
C & -0.061 & -0.032 \\
A & -0.054 & 0.034 \\
G & 0.023 &
\end{tabular}

codon preference on gene expression was weaker than the effect of amino acid composition.

Table 3 shows the observed number of combinations of nucleotides at the third position and their 3' adjacent nucleotides. From this table, we can see the number of Cs at the third position of codons is significantly smaller than that of Ts when the 3' adjacent nucleotide is G (p $<0.1 \%$, chi-square test). This finding indicates that codon preference in the mouse genome is affected by CpG hypermutability.

\section{Discussion}

\section{Variation of gene expression level}

There is a large variation among gene expression level [33]. More than $90 \%$ of variation of expression levels cannot be explained by amino acid components. Gene expression levels are known to be affected by many factors, such as 3'UTR lengths [41]. Further study must be necessary.

\section{Amino acid contents and gene expression level}

To our knowledge, this is the first study that showed amino acid composition depends on the gene expression level in mouse. Previous study has shown that, in the case of budding yeast, some residues showed a positive correlation, and most of these residues were small [8]. Furthermore, Akashi and Gojobori [31] showed an increase in the abundance of less energetically costly amino acids in highly expressed proteins. This study also suggested that natural selection for energetic efficiency appears to constrain the primary structures of the proteins of Bacillus subtilis and E. coli [31]. Amino acid mutations that do not cause changes in protein functions may result in subtle, but evolutionarily important, fitness consequences through their effects on translation and metabolism.

We compared the estimates of the cost of amino acid synthesis from the above mentioned study [31] to the

Table 3 Observed number of combinations of nucleotide at the third position and their $3^{\prime}$ adjacent nucleotide

\begin{tabular}{|c|c|c|c|c|c|c|c|}
\hline \multirow[b]{2}{*}{$\begin{array}{l}\text { Codon } \\
\text { type }\end{array}$} & \multirow[b]{2}{*}{$\begin{array}{c}\text { Third } \\
\text { nucleotide }\end{array}$} & \multicolumn{6}{|c|}{ The $3^{\prime}$ adjacent nucleotide } \\
\hline & & $\mathbf{T}$ & $\mathrm{C}$ & A & G & & $\mathrm{H}$ \\
\hline \multirow[t]{2}{*}{ All } & $\mathrm{T}$ & 45922 & 71142 & 48193 & 135728 & & 165257 \\
\hline & C & 88111 & 113015 & 141307 & 45671 & $* *$ & 342433 \\
\hline \multirow{2}{*}{$\begin{array}{l}\text { T- } \\
\text { adapted }\end{array}$} & T & 24963 & 42070 & 22892 & 64855 & & 89925 \\
\hline & C & 44589 & 54213 & 72472 & 21423 & $* *$ & 171274 \\
\hline \multirow{2}{*}{$\begin{array}{l}\text { C- } \\
\text { adapted }\end{array}$} & T & 20959 & 29072 & 25301 & 70873 & & 75332 \\
\hline & C & 43522 & 58802 & 68835 & 24248 & $* *$ & 171159 \\
\hline
\end{tabular}

H stands for A, C, or T.

** Significantly lower than the number of Cs when the $3^{\prime}$ adjacent nucleotide is $\mathrm{H}(\mathrm{p}<0.1 \%)$ after Bonferroni correction when a chi-square test was used. 
correlation coefficients presented in Table 1 (data not shown); however, we determined that the correlation was insignificant. It may be difficult to estimate the accurate metabolic cost of each amino acid, because the mouse obtains amino acids from food. Furthermore, the cost may depend on the environment. In the case of mouse, 10 amino acids, namely, Arg, His, Ile, Leu, Lys, Met, Phe, Thr, Try, and Val, are essential for natural growth [42]. Thus, sparing the incorporation of His and Ile in highly expressed proteins may be advantageous to the mouse. However, Cys is not an essential amino acid, and is negatively correlated with gene expression. Of note, both amino acid composition and gene expression level may be influenced by protein functions. Furthermore, adaptive changes in protein sequences may overcome the increases in the metabolic cost, and the amino acid sequences may not be optimized for metabolic cost. Further study is necessary to elucidate these issues. Our results show that the coefficient of determination is very small so that it would be hard to predict expression level from amino acid contents in mammals.

\section{Codon preference and gene expression level}

We determined that the effect of codon preference on gene expression was weaker than the effect of amino acid composition, because no significant correlations were observed with respect to codon preference. This result is consistent with the relationship between codon bias and expression level, as proposed by the translation-selection model, is less evident in mammals [22-30]. In mammals, it would also be hard to predict expression level from codon bias.

\section{CpG hypermutability}

Hypermutability of CpG dinucleotides [43] is one of major causes of codon substitution in mammalian genes [44-48]. CpG dinucleotides are often methylated at sites of cytosine (C); subsequently, the methylated C spontaneously deaminates to thymine $(\mathrm{T})$ with a higher frequency than that of other types of point mutations [49]. It has previously been estimated that approximately $14 \%$ of codon substitutions are caused by hypermutations at CpG sites [36]. Furthermore, CpG hypermutation has been shown to affect the rate of amino acid substitution [39].

Table 2 shows that gene expression levels do not significantly affect codon preference in mouse. Furthermore, Table 3 indicates that the effect of codon preference is weaker than that of CpG hypermutability. Thus, the relationship between codon bias and gene expression level can be explained on the basis of the translation-selection model [2]. This model proposes that codon usage in highly expressed genes is biased toward "optimal" codons, i.e., codons corresponding to more abundant tRNAs. This bias has been demonstrated to affect both elongation rate and accuracy [50,51]. As shown in Table 2, the calculated negative correlation indicates that the codons used in this study are not optimal. In human and mouse genomes, the most frequently used codons [52] are not those with the most abundant tRNAs [35].

Recent studies [36,39] have shown that CpG mutation rates in the non-coding regions of the human genome negatively correlate with the local GC content [53-56]. Isochores of the human genome [57] appear to be an influential factor that affects codon composition [53-56], and several studies have shown that this factor is related to gene expression levels $[58,59]$. However, additional studies are necessary to confirm the relationship between codon bias and the positional effect of genes.

Plotkin et al. [24] showed that codon usage for tissuespecific genes varies among the tissues in which such genes are expressed, thereby suggesting that this variation may be affected by differential tRNA-gene copy numbers in different tissues. However, this variability in codon usage among tissues is still under debate $[22,60,61]$. Nevertheless, it is noteworthy that codon substitutions are affected by adjacent codons [36,39], and are therefore indirectly affected by adjacent amino acids [38]. Amino acid frequencies may also be tissue specific, although additional studies are necessary to investigate the effect of CpG hypermutability on tissuespecific codon usage. Furthermore, codon bias in mammalian genomes should also be investigated with regard to the presence of CpG nucleotides [27,28,30].

\section{Conclusion}

In mouse, the effect of gene expression level on codon bias is weaker than both the effect of gene expression level on amino acid composition and the effect of CpG hypermutability on codon bias. However, to detect the effect of gene expression level on codon bias in mouse, a study of more genes is necessary.

\section{Acknowledgements}

We thank Dr. Osamu Ohara and all members of the Human Genetics Laboratory of Kazusa DNA research institutes for their encouragement and useful comments on the manuscript. The present study was supported by the National Project on "Next-generation Integrated Living Matter Simulation" of the Ministry of Education, Culture, Sports, Science and Technology (MEXT).

\section{Author details}

${ }^{1}$ Research Program for Computational Science, Research and Development Group for Next-Generation Integrated Living Matter Simulation, Fusion of Data and Analysis Research and Development Team, RIKEN, 4-6-1 Shirokanedai, Minato-ku, Tokyo 108-8639, Japan. ${ }^{2}$ Chiba Industry Advancement Center, 2-6 Nakase, Mihama-ku, Chiba 261-7126, Japan. ${ }^{3}$ Kazusa DNA Research Institute, 2-6-7 Kazusa-Kamatari, Kisarazu, Chiba 292-0818, Japan.

\section{Authors' contributions}

KM wrote the software and the manuscript. RFK supervised the project. Both authors read and approved the final manuscript. 


\section{Competing interests}

The authors declare that they have no competing interests.

Received: 25 June 2010 Accepted: 27 January 2011

Published: 27 January 2011

\section{References}

1. Miyata T, Hayashida H, Yasunaga T, Hasegawa M: The preferential codon usages in variable and constant regions of immunoglobulin genes are quite distinct from each other. Nucleic Acids Res 1979, 7(8):2431-2438.

2. Akashi $\mathrm{H}$, Eyre-Walker $\mathrm{A}$ : Translational selection and molecular evolution. Curr Opin Genet Dev 1998, 8(6):688-693.

3. Willie E, Majewski J: Evidence for codon bias selection at the pre-mRNA level in eukaryotes. Trends Genet 2004, 20(11):534-538

4. Sharp PM, Bailes E, Grocock RJ, Peden JF, Sockett RE: Variation in the strength of selected codon usage bias among bacteria. Nucleic Acids Res 2005, 33(4):1141-1153.

5. Karlin S, Barnett MJ, Campbell AM, Fisher RF, Mrazek J: Predicting gene expression levels from codon biases in alpha-proteobacterial genomes. Proc Natl Acad Sci USA 2003, 100(12):7313-7318.

6. Roymondal U, Das S, Sahoo S: Predicting gene expression level from relative codon usage bias: an application to Escherichia coli genome. DNA Res 2009, 16(1):13-30.

7. Henry I, Sharp PM: Predicting gene expression level from codon usage bias. Mol Biol Evol 2007, 24(1):10-12.

8. Raghava GP, Han JH: Correlation and prediction of gene expression level from amino acid and dipeptide composition of its protein. $B M C$ Bioinformatics 2005, 6:59.

9. Raghava GP, Han JH, Hwang DJ: ECGpred: Correlation and prediction of gene expression from nucleotide sequence. The Open Bioinformatics Journal 2008, 2:64-71.

10. Jansen R, Bussemaker HJ, Gerstein M: Revisiting the codon adaptation index from a whole-genome perspective: analyzing the relationship between gene expression and codon occurrence in yeast using a variety of models. Nucleic Acids Res 2003, 31(8):2242-2251.

11. Beer MA, Tavazoie S: Predicting gene expression from sequence. Cell 2004, 117(2):185-198

12. Coghlan A, Wolfe KH: Relationship of codon bias to mRNA concentration and protein length in Saccharomyces cerevisiae. Yeast 2000, 16(12):1131-1145.

13. Ikemura T: Codon usage and tRNA content in unicellular and multicellular organisms. Mol Biol Evol 1985, 2(1):13-34.

14. Bennetzen JL, Hall BD: Codon selection in yeast. J Biol Chem 1982, 257(6):3026-3031.

15. Ikemura T: Correlation between the abundance of yeast transfer RNAs and the occurrence of the respective codons in protein genes. Differences in synonymous codon choice patterns of yeast and Escherichia coli with reference to the abundance of isoaccepting transfer RNAs. J Mol Biol 1982, 158(4):573-597.

16. Akashi H: Inferring weak selection from patterns of polymorphism and divergence at "silent" sites in Drosophila DNA. Genetics 1995, 139(2):1067-1076.

17. Akashi H: Translational selection and yeast proteome evolution. Genetics 2003, 164(4):1291-1303.

18. Duret $L:$ tRNA gene number and codon usage in the $C$. elegans genome are co-adapted for optimal translation of highly expressed genes. Trends Genet 2000, 16(7):287-289.

19. Marais $G$, Duret L: Synonymous codon usage, accuracy of translation, and gene length in Caenorhabditis elegans. J Mol Evol 2001, 52(3):275-280.

20. Moriyama EN, Powell JR: Codon usage bias and tRNA abundance in Drosophila. J Mol Evol 1997, 45(5):514-523.

21. Musto H, Cruveiller S, D'Onofrio G, Romero H, Bernardi G: Translational selection on codon usage in Xenopus laevis. Mol Biol Evol 2001, 18(9):1703-1707.

22. Urrutia AO, Hurst LD: Codon usage bias covaries with expression breadth and the rate of synonymous evolution in humans, but this is not evidence for selection. Genetics 2001, 159(3):1191-1199.

23. Urrutia AO, Hurst LD: The signature of selection mediated by expression on human genes. Genome Res 2003, 13(10):2260-2264

24. Plotkin JB, Robins H, Levine AJ: Tissue-specific codon usage and the expression of human genes. Proc Natl Acad Sci USA 2004, 101(34):12588-12591.
25. Lavner $\mathrm{Y}$, Kotlar D: Codon bias as a factor in regulating expression via translation rate in the human genome. Gene 2005, 345(1):127-138

26. Kotlar D, Lavner $Y$ : The action of selection on codon bias in the human genome is related to frequency, complexity, and chronology of amino acids. BMC Genomics 2006, 7:67.

27. Hellmann I, Zollner S, Enard W, Ebersberger I, Nickel B, Paabo S: Selection on human genes as revealed by comparisons to chimpanzee cDNA. Genome Res 2003, 13(5):831-837.

28. Kondrashov FA, Ogurtsov AY, Kondrashov AS: Selection in favor of nucleotides $\mathrm{G}$ and $\mathrm{C}$ diversifies evolution rates and levels of polymorphism at mammalian synonymous sites. J Theor Biol 2006, 240(4):616-626.

29. Subramanian S: Nearly neutrality and the evolution of codon usage bias in eukaryotic genomes. Genetics 2008, 178(4):2429-2432.

30. dos Reis $M$, Wernisch L: Estimating translational selection in eukaryotic genomes. Mol Biol Evol 2009, 26(2):451-461.

31. Akashi H, Gojobori T: Metabolic efficiency and amino acid composition in the proteomes of Escherichia coli and Bacillus subtilis. Proc Natl Acad Sci USA 2002, 99(6):3695-3700

32. Herbeck JT, Wall DP, Wernegreen JJ: Gene expression level influences amino acid usage, but not codon usage, in the tsetse fly endosymbiont Wigglesworthia. Microbiology 2003, 149(Pt 9):2585-2596.

33. Koga H, Yuasa S, Nagase T, Shimada K, Nagano M, Imai K, Ohara R, Nakajima D, Murakami $\mathrm{M}$, Kawai $\mathrm{M}$, et al: A comprehensive approach for establishment of the platform to analyze functions of KIAA proteins II: public release of inaugural version of InGaP database containing gene/protein expression profiles for 127 mouse KIAA genes/proteins. DNA Res 2004, 11(4):293-304.

34. Kikuno R, Nagase T, Nakayama M, Koga H, Okazaki N, Nakajima D, Ohara O: HUGE: a database for human KIAA proteins, a 2004 update integrating HUGEppi and ROUGE. Nucleic Acids Res 2004, , 32 Database: D502-504.

35. Chan PP, Lowe TM: GtRNAdb: a database of transfer RNA genes detected in genomic sequence. Nucleic Acids Res 2009, 37 Database: D93-97.

36. Misawa K, Kikuno RF: Evaluation of the effect of CpG hypermutability on human codon substitution. Gene 2009, 431(1-2):18-22.

37. Eyre-Walker AC: An analysis of codon usage in mammals: selection or mutation bias? J Mol Evol 1991, 33(5):442-449

38. Wang $G Z$, Chen $L L$, Zhang HY: Neighboring-site effects of amino acid mutation. Biochem Biophys Res Commun 2007, 353(3):531-534.

39. Misawa K, Kamatani N, Kikuno RF: The universal trend of amino acid gainloss is caused by CpG hypermutability. J Mol Evol 2008, 67(4):334-342.

40. R Development Core Team: R: A language and environment for statistical computing. Vienna, Austria; 2008

41. Okazaki N, Imai K, Kikuno RF, Misawa K, Kawai M, Inamoto S, Ohara R, Nagase T, Ohara O, Koga H: Influence of the 3'-UTR-length of mKIAA cDNAs and their sequence features to the mRNA expression level in the brain. DNA Res 2005, 12(3):181-189.

42. John AM, Bell JM: Amino acid requirements of the growing mouse. J Nutr 1976, 106(9):1361-1367.

43. Bird AP: DNA methylation and the frequency of $\mathrm{CpG}$ in animal DNA. Nucleic Acids Res 1980, 8(7):1499-1504

44. Jukes TH: Codons and nearest-neighbor nucleotide pairs in mammalian messenger RNA. J Mol Evol 1978, 11(2):121-127.

45. Karlin S, Mrazek J: What drives codon choices in human genes? J Mol Biol 1996, 262(4):459-472

46. Krajewski C, Blacket M, Buckley L, Westerman M: A multigene assessment of phylogenetic relationships within the dasyurid marsupial subfamily Sminthopsinae. Mol Phylogenet Evol 1997, 8(2):236-248

47. Huttley GA: Modeling the impact of DNA methylation on the evolution of BRCA1 in mammals. Mol Biol Evol 2004, 21(9):1760-1768.

48. Lunter G: Probabilistic whole-genome alignments reveal high indel rates in the human and mouse genomes. Bioinformatics 2007, 23(13):i289-296.

49. Scarano E, laccarino M, Grippo P, Parisi E: The heterogeneity of thymine methyl group origin in DNA pyrimidine isostichs of developing sea urchin embryos. Proc Natl Acad Sci USA 1967, 57(5):1394-1400.

50. Bulmer M: The selection-mutation-drift theory of synonymous codon usage. Genetics 1991, 129(3):897-907.

51. Akashi H: Synonymous codon usage in Drosophila melanogaster: natural selection and translational accuracy. Genetics 1994, 136(3):927-935.

52. Nakamura Y, Gojobori T, Ikemura T: Codon usage tabulated from international DNA sequence databases: status for the year 2000. Nucleic Acids Res 2000, 28(1):292 
53. Fryxell KJ, Moon WJ: CpG mutation rates in the human genome are highly dependent on local GC content. Mol Biol Evol 2005, 22(3):650-658.

54. Taylor J, Tyekucheva S, Zody M, Chiaromonte F, Makova KD: Strong and weak male mutation bias at different sites in the primate genomes: insights from the human-chimpanzee comparison. Mol Biol Evol 2006, 23(3):565-573.

55. Tyekucheva S, Makova KD, Karro JE, Hardison RC, Miller W, Chiaromonte F: Human-macaque comparisons illuminate variation in neutral substitution rates. Genome Biol 2008, 9(4):R76.

56. Walser JC, Ponger L, Furano AV: CpG dinucleotides and the mutation rate of non-CpG DNA. Genome Res 2008, 18(9):1403-1414

57. Bernardi G: The vertebrate genome: isochores and evolution. Mol Biol Evol 1993, 10(1):186-204.

58. Vinogradov AE: Isochores and tissue-specificity. Nucleic Acids Res 2003, 31(17):5212-5220.

59. Vinogradov AE: Noncoding DNA, isochores and gene expression: nucleosome formation potential. Nucleic Acids Res 2005, 33(2):559-563.

60. Hsiao LL, Dangond F, Yoshida T, Hong R, Jensen RV, Misra J, Dillon W, Lee KF, Clark KE, Haverty P, et al: A compendium of gene expression in normal human tissues. Physiol Genomics 2001, 7(2):97-104.

61. Semon M, Lobry JR, Duret L: No evidence for tissue-specific adaptation of synonymous codon usage in humans. Mol Biol Evol 2006, 23(3):523-529.

doi:10.1186/1756-0500-4-20

Cite this article as: Misawa and Kikuno: Relationship between amino acid composition and gene expression in the mouse genome. BMC Research Notes 2011 4:20.

\section{Submit your next manuscript to BioMed Central and take full advantage of:}

- Convenient online submission

- Thorough peer review

- No space constraints or color figure charges

- Immediate publication on acceptance

- Inclusion in PubMed, CAS, Scopus and Google Scholar

- Research which is freely available for redistribution

Submit your manuscript at www.biomedcentral.com/submit 